\title{
EFFECT OF PLACENTAL CORD BLOOD DRAINAGE ON THE THIRD STAGE OF LABOUR.
}

Sreelatha $\mathrm{S}^{1}$, Dr. Vedavathy Nayak², Dr Ayisha Kazi³

1. Associate Professor, Department of Obstetrics \& Gynaecology, ESICMC \& PGIMSR, Rajajinagar, Bangalore

2. Assistant Professor, Department of Obstetrics \& Gynaecology, ESICMC \& PGIMSR, Rajajinagar, Bangalore

3. Junior Resident, Department of Obstetrics \& Gynaecology, ESICMC \& PGIMSR, Rajajinagar, Bangalore

\section{CORRESPONDING AUTHOR:}

Dr. Sreelatha S, ESICMC \& PGIMSR, Rajajinagar,

3rd Block, Bangalore 560010,

E-mail: drsreelatha2011@gmail.com

\begin{abstract}
OBJECTIVE: To assess the effect of placental blood drainage on the third stage of labor. METHOD: A prospective study was carried out on 100 women having vaginal delivery. In the study group ( 50 women), the placental end of the cut umbilical cord was unclamped immediately after cutting the cord and in the control group (50 women) it remained clamped. The duration of the third stage and amount of blood loss were noted. The result was analysed by t test. RESULTS: The mean duration of the third stage was $4.14+/-1.67$ minutes in the study group and $7.990+/-5.77$ minutes in the control group. The average amount of blood loss was 209+/-56.07 $\mathrm{ml}$ in the study group and $241.27+/-94.70$ in the control group. Retained placenta was reported in 3 cases in the control group and none in the study group. 3 patients in the control group had PPH, out of which 2 needed blood transfusions. CONCLUSION: Placental blood drainage is a simple and effective method in decreasing the duration and amount of blood loss in the third stage of labor.
\end{abstract}

KEYWORDS: placental cord blood drainage, third stage of labour, retained placenta, postpartum haemorrhage

INTRODUCTION; The third stage of labor starts after the delivery of the fetus to the expulsion of placenta and fetal membranes. Postpartum haemorrhage is the most common dreaded complication and the most common cause of maternal mortality. Management of the third stage of labor can be active management or expectant management.

The active management involves administration of oxytocic drugs, clamping and cutting the cord as well as controlled cord traction. Unclamping the cord at maternal side and releasing of placental blood has been suggested for facilitating delivery of the placenta it is physiologically plausible that draining blood from the placenta would reduce its bulkiness allowing the uterus to contract and retract effectively leading to delivery of the placenta and may reduce the duration of the 3rd stage of labour.(1)

MATERIALS AND METHODS: This was a prospective study on 100 women having vaginal delivery admitted to the labor ward at ESICMC \& PGIMSR, Rajajinagar, Bangalore. The inclusion criteria were full term singleton, pregnancy, with vertex presentation expected to have spontaneous vaginal delivery. The exclusion criteria were hemoglobin less than $8 \mathrm{~g} / \mathrm{dL}$, overdistended uterus 
(hydramnios, multiple pregnancy, and large baby), antepartum hemorrhage, induced labor, instrumental delivery and known coagulation disorders. After a detailed history taking, general physical and obstetric examination was performed. Informed consent was taken from those who fulfilled the inclusion criteria. Once the women delivered vaginally without any instrumentation, they were randomized into 2 groups (study and control groups). In the study group, the placental end of the cut umbilical cord was unclamped immediately after it was cut and left open to drain blood in a vessel until the flow ceased. This prevented the drained blood from getting mixed with blood lost in the third stage. In the control group placental end of the cut umbilical cord remained clamped. Blood lost in the third stage was collected in a clean metal bowl which was kept at the tail end of a Kelley's pad which was used during delivery. Once the signs of placental separation were seen, placenta was delivered by controlled cord traction. The duration of third stage was calculated using a stopwatch. If there was excessive bleeding due to uterine atony 10 units oxytocin in $500 \mathrm{~mL}$ of saline drip was started. If the uterus was still atonic, prostadin (PGF2a) $250 \mathrm{mg}$ was given intramuscularly. The blood collected in the metal bowl was measured using a measuring jar. Care was taken not to mix the drained blood from the cord with the blood lost during the third stage.

The pulse rate, blood pressure and state of the uterus were noted immediately after delivery. The women were observed for any complications for the next one hour. Blood transfusion was given if indicated.

The duration of the third stage of labour and the amount of blood loss were the primary outcome measures whereas the incidence of PPH, retained placenta and the need for blood transfusion were the secondary outcome measures. Mean and standard deviation of the parameters were calculated and t-test was used for statistical analysis. P value $<0.05$ was taken as significant.

RESULTS: The two groups were well matched with respect to baseline characteristics (Table 1). The average duration of the third stage of labour was 4.14+/-1.67 minutes in the study group and $7.990+/-5.77$ minutes in the control group. The difference was highly significant $(\mathrm{p}<0.05)$. The average amount of blood loss in the third stage was $209+/-56.07 \mathrm{ml}$ in the study group and $241.27+/-94.70 \mathrm{ml}$ in the control group. The difference was significant $(\mathrm{p}<0.05$ ) [Table 2].

There was 1 case of retained placenta in the control group which required manual removal under general anaesthesia and none in the study group. Postpartum haemorrhage occurred in 3 cases in the control group out of which 2 required blood transfusion. There were no cases of PPH in the study group.

Table 1. Baseline characteristics of study and control group (mean +/- SD).

\begin{tabular}{|l|l|l|l|}
\hline Parameters & Study group & Control group & value \\
\hline Age (years) & $23.20+/-2.57$ yrs & $24+/-2.92$ yrs & 0.1437 \\
\hline Parity & $1.36+/-0.48$ & $1.33+/-0.59$ & 0.8036 \\
\hline Gestational age (weeks) & $38.7+/-1$ & $38.78+/-0.81$ & 0.6415 \\
\hline $\begin{array}{l}\text { Hemoglobin levels } \\
\text { (gm/dl) }\end{array}$ & $11.162+/-1.85$ & $10.9+/-0.846$ & 0.3835 \\
\hline
\end{tabular}




\section{ORIGINAL ARTICLE}

Table 2. Outcome of the study

\begin{tabular}{|l|l|l|l|}
\hline Parameters & Study group & Control group & p value \\
\hline $\begin{array}{l}\text { Duration of third stage of } \\
\text { labor (minutes) }\end{array}$ & $4.14+/-1.67$ & $7.990+/-5.77$ & 0.00003 \\
\hline Amount of blood loss(ml) & $209+/-56.07$ & $241.27+/-94.70$ & 0.0367 \\
\hline $\begin{array}{l}\text { Retained placenta } \\
\text { [removed by manual } \\
\text { removal] (no.) }\end{array}$ & 0 & 1 & \\
\hline $\begin{array}{l}\text { Postpartum haemorrhage } \\
\text { (no.) }\end{array}$ & 0 & 3 & \\
\hline Blood transfusion (no.) & 0 & 2 & \\
\hline
\end{tabular}

DISCUSSION: The third stage of labour begins immediately after the birth of the baby and ends with the expulsion of the placenta and fetal membranes. Reduced uterine size and limited placental elasticity and a tight compression by the uterus lead to separation of the placenta from the spongy decidua (lining of the uterus). Placental cord drainage involves the clamping and cutting of the umbilical cord after delivery of the baby but, afterwards, immediately unclamping the maternal side of the cord and allowing the blood to drain freely. The Cochrane data base of systematic review studied the effect of placental cord drainage on the 3rd stage of labour and concluded that cord drainage resulted in statistically significant reduction in the length of 3rd stage of labour(1)

In a randomized control study comparing 239 women who had placental cord drainage with 238 women with expectant delivery of the placenta, Giacalone et al reported the median value of the duration of the $3^{\text {rd }}$ stage of labour was 8 minutes in cord drainage group and 15 minutes in the control group(2)

Gulati et al studied 200 women to evaluate placental blood drainage during vaginal delivery as a method of shortening the duration of 3rd stage and reducing the amount of blood loss and concluded that duration of 3rd stage of labour in the control group was 5.72 minutes and in the study group it was 2.94 minutes, the amount of blood lost in the 3rd stage was $247.59 \mathrm{ml}$ in the control group and $193.63 \mathrm{ml}$ in the study group. Incidence of pph was $12 \%$ in the control and $6 \%$ in the study group. Retained placenta was observed in $4 \%$ in the control group and $0 \%$ in the study group (3)

Sharma et al reported a study on 958 women having vaginal delivery, who were randomized to the drainage method (478 women) or control cord traction method (480 women) for placental delivery, the mean duration of 3rd stage of labour was 3.24 minutes and 3.2 minutes in the placental drainage group in contrast to 8.57 minutes and 6.2 minutes in controlled cord traction method in primigravida and multigravida respectively (4).

Shravage J and Silpa P in their study found that the duration of 3rd stage was 5 minutes in the study group and 7.4 minutes in the control group. The average blood loss was $175 \mathrm{ml}$ in the study group and $252 \mathrm{ml}$ in the control group (5).

The results of the above 2 studies are comparable with the results of our study.

There is some evidence that placental cord drainage may reduce fetomaternal transfusion which can occur with placental separation as there is small risk that the baby's blood cells may get into 
the mother circulation and stimulate antibody production (isoimmunization)(6,7)

Further studies are needed to assess the effect of placental blood drainage on maternal and neonatal outcome.

CONCLUSION: Placental cord blood drainage is a safe and effective method of reducing the duration of the third stage of labour. It is also an effective intervention for reducing the amount of blood loss in the third stage. As there is no extra cost or equipment involved, it may be especially relevant in facilities with poor infrastructure.

\section{REFERENCES}

1. Soltani H, Dickinson F, Symonds I. Placental cord drainage after spontaneous vaginal delivery as a part of the management of the third stage of labour. Cochrane data base of systematic reviews 2005 .

2. Giacalone PL, Vignal J, Daures JP et al. A randomized evaluation of two techniques of management of the third stage of labour in women at low risk of postpartum hemorrhage. Br J Obstet Gynaecol 2000; 107(3):396-400.

3. Gulati N, Chauhan MD, Rana M. Placental blood drainage in the management of third stage of labour. J Obstet. \& Gynecol India 2001; 51:46-8.

4. Sharma JB, Pundir Pet al. Evaluation of placental drainage as a method of placental delivery in vaginal deliveries. Arch. Gynecol. Obstet. 2005; 271:343-5.

5. Shravage JC, Silpa P. Randomized controlled trial of placental blood drainage for the prevention of postpartum hemorrhage. J Obstet Gynecol India 2007; (3):214-6.

6. Gill Gyte. NCT evidence based briefing third stage of labour. New Digest; 2006: 22-23.

7. Prendiville WJ, Elbourne D. Care during the third stage of labour. Oxford: Oxford University Press; 1989; 1145-69. 